Saudi Journal of Oral and Dental Research

Abbreviated Key Title: Saudi J Oral Dent Res

ISSN 2518-1300 (Print) |ISSN 2518-1297 (Online)

Scholars Middle East Publishers, Dubai, United Arab Emirates

Journal homepage: https://saudijournals.com/sjodr

\title{
Erudition and Cognizance about Protocol during COVID-19 Pandemic among Dental Students of Saudi Arabia
}

Mohammed S Alsahhar", Amani Salem Alkhybari, Malek Ahmed Mohammedsaleh, Sultan Mohammed Aljumah, Naif Saud Alosaimi, Amjad Talal Aljumaydi, Khalid Meshari Almutairi, Fatima Sultana

Alfarabi College, Community Science, Saudi Arabia

DOI: $10.36348 /$ sjodr.2020.v05i09.009

| Received: 30.08 .2020 | Accepted: 07.09.2020 | Published: 17.09.2020

*Corresponding author: Mohammed S Alsahhar

\section{Abstract}

As reported by WHO on $18^{\text {th }}$ July, there are a total of $13,876,441$ and 593,087 confirmed deaths due to covid-19. About 216 countries or areas are affected with Covid-19 disease. The most probable origin of COVID-19 virus being Chinese horseshoe bat (Rhinolophus Sinicus) and pangolins as the intermediate host. The outbreak of the COVID-19 viral disease is considered to be Health Emergency and has spread to different parts of the world. There is a high risk of crossinfection to occur between the dentist and the patient due to the setting of the dental clinic. During the dental procedures a large number of droplets and aerosols that are released in the environment can contaminate the clinic even during the incubation period or in case with asymptomatic patients and hence the standard cleaning techniques wont work and requires special sanitization. According to the MOH guidelines during the COVID-19 pandemic in Saudi Arabia, strict guidelines and protocol need to be followed for the prevention of infection and as control measures for the spread of the COVID-19 virus. As per the report of WHO on $18^{\text {th }}$ July, there are a total of 13,876,441 and 593,087 confirmed deaths due to covid-19. The statistics on $4^{\text {th }}$ August showed a total of 281,000 confirmed covid-19 cases in Saudi Arabia, with 244,000 people recovered from the disease and 2984 deaths in total and remaining under treatment. The survey of this study showed results that more than $90 \%$ of the dental students have good knowledge about COVID-19 pandemic and dentistry. The dental students are well aware of the protocol to be followed during the dental practices. Very few surveys are done all across the world on the present topic as this is only half a year since emergence of the COVID-19 virus.

Keywords: Covid-19, WHO, Health emergency, viral disease, MOH guidelines, dentistry, dental care protocol.

Copyright @ 2020: This is an open-access article distributed under the terms of the Creative Commons Attribution license which permits unrestricted use, distribution, and reproduction in any medium for non-commercial use (NonCommercial, or CC-BY-NC) provided the original author and source are credited.

\section{INTRODUCTION}

In 2020 , on January $30^{\text {th }}$ the novel coronavirus that is the causative virus for COVID-19 disease in china, was declared as an emergency for the public health globally by World Health Organization (WHO) [1]. As reported by WHO on $18^{\text {th }}$ July, there are a total of 13,876,441 and 593,087 confirmed deaths due to covid-19. About 216 countries or areas are affected with Covid-19 disease [1].

COVID-19 stands for (CO) Corona, (VI) Viruses, (D) Disease (19) its a disease reported in the year 2019. Covid-19 is an infectious disease caused by new strain of corona-viruses. Covid-19 virus is a new type of virus that is linked with the same family of viruses like the severe acute respiratory syndrome (SARS) and some common cold type of viruses [2].

According to a recent research by Chinese Preventive Medicine Association it was confirmed that
COVID-19 virus is zoonotic like similar to severe acute respiratory syndrome coronavirus (SARS-CoV) and Middle East respiratory syndrome coronavirus (MERS$\mathrm{CoV}$ ) [3]. The most probable origin of COVID-19 virus being Chinese horseshoe bat (Rhinolophus Sinicus) and pangolins as the intermediate host [4].

The common symptoms of covid-19 includes fever, cough, shortness of breath and in severe cases the infection may cause the pneumonia and breathing difficulty and very rarely that disease can be fatal. Most of the sentence of covid-19 resemble to that of influenza or common cold and hence the testing is required to confirm that someone is covid positive or not [5].

The mode of Transmission for covid-19 is direct contact or with respiratory droplets of an infected person and can be transmitted by touching Surfaces contaminated by the covid-19 virus and by touching 
their face specially the eyes, nose and mouth. The covid-19 virus survive on surfaces for several hours and the simple disinfectant can be used to kill the virus [6]. The older people and people with chronic medical conditions are at more at risk of developing severe symptoms [1].

People of any age can be infected with this virus and research is going on with how the virus infects the children. There is currently no vaccine available for Covid-19. Many of the symptoms are however if treated at early stages can avoid critical conditions. Several clinical trials are presently conducted to determine the therapeutics for Covid-19. The spread of Covid-19 can be prevented by washing hands with soap and water; staying at home most of the times; by covering mouth and nose when going out; sanitizing frequently touiched surfaces.

The outbreak of the COVID-19 viral disease is considered to be Health Emergency and has spread to different parts of the world. Airborne transmission over long distances by the COVID-19 virus has not been researched and documented as its difficult to detect directly the virus in the air [8].

A hypothesis claims that airborne transmissions was partially responsible for large number of transmission of infections. Despite all the evidences and hypothesis, globally the old way of thinking is accepted that infection transfers only through direct contact. Both symptomatic and asymptomatic patients with COVID-19 are the carriers for this virus. The present observations of this outbreak suggests that people of all ages are susceptible to this new COVID-19 virus.

\section{COVID-19 and Dentistry}

There is a high risk of cross-infection to occur between the dentist and the patient due to the setting of the dental clinic. In countries that are mostly affected by the COVID-19 virus, the dental practices need to follow a strict guideline and infection control protocol of working to avoid the contact of infection between the dental staff and the patient [9].

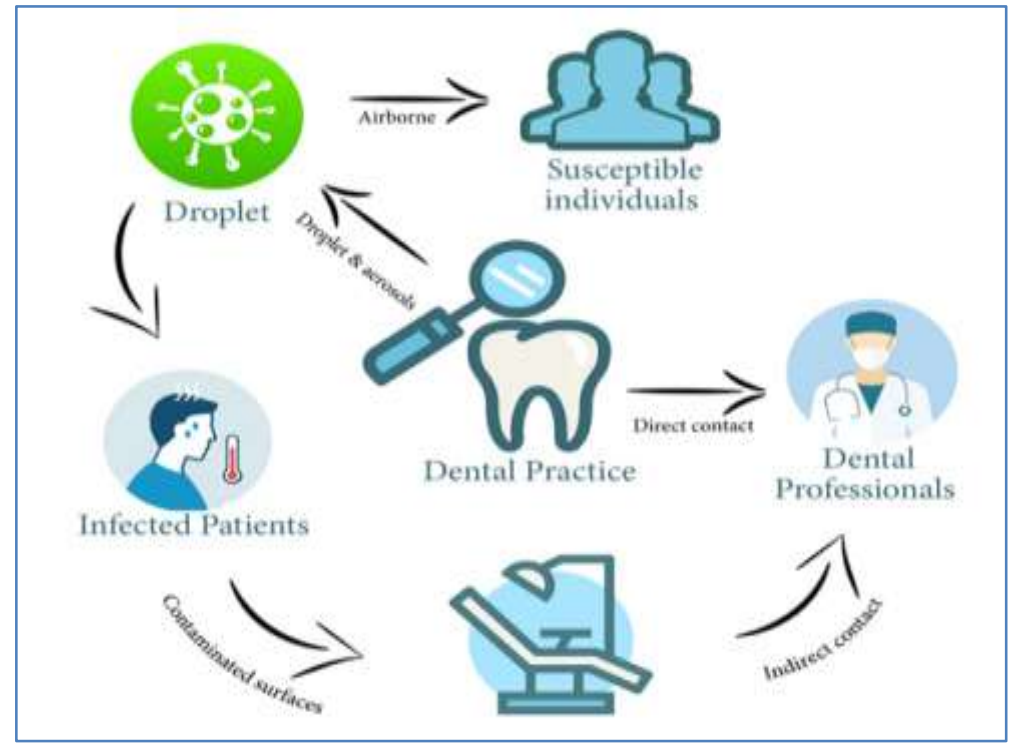

Illustration of mode of transmission of COVID-19 in the Dental Clinic

The patient that is under the dental treatment may transfer the secretions, saliva and blood aerosols to the surrounding space in the dental clinic by sneezing, coughing or receiving treatment by high-speed handpiece or ultrasonic dental instruments [9]. The patient may be at a risk of infection from the contaminated dental apparatus or clinic environment. Whereas the dentist may be at a risk of infection from the infected patient through the puncture of sharp instruments and a direct contact between the mucous membrane and the dentist hands [9]. 


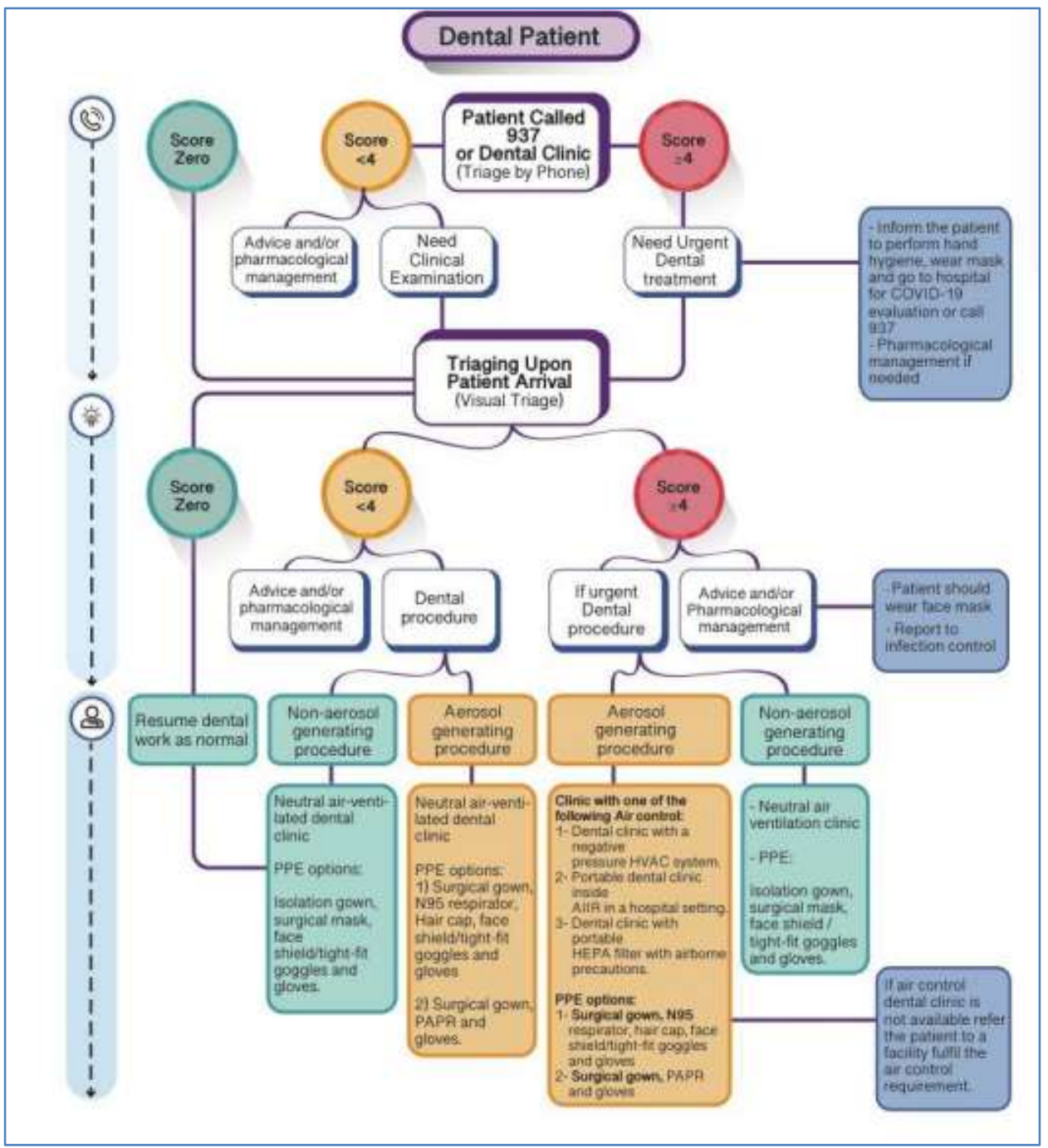

Infection Control Measures Flow Chart for Dental Treatment during COVID-19 Pandemic

During the dental procedures a large number of droplets and aerosols that are released in the environment can contaminate the clinic even during the incubation period or in case with asymptomatic patients and hence the standard cleaning techniques won't work and requires special sanitization [9]. Preventive measures like good hand hygiene is given utmost importance along with using personal protective equipments like gloves, masks, gown. Face shield and goggles to avoid the infection of the skin and mucosa with the COVID-19 virus. N-95 mask or FFP2 masks are recommended for usage during the dental procedures. The N-95 mask was authenticated by the National institute for the occupational safety and health. The FFP2 mask was authenticated by the European union [9].

According to the MOH guidelines during the COVID-19 pandemic in Saudi Arabia, strict guidelines and protocol need to be followed for the prevention of infection and as control measures for the spread of the COVID-19 virus [9]. The routinely dental practices are to be avoided for the time being to deal with the epidemic situation. Any dental staff if suffering with fever, cough, sneezing and other COVID-19 symptoms should stop to work and isolate and undergo medical examination [9].

A document of the guidelines and protocols to be followed while working in the dental clinic was issued by the Ministry of Health in Saudi Arabia that targeted the dentists, dental assistants, hygienists, dental technicians working in the dental clinics or dental departments of the hospitals [9]. All the guideline was according to the guidance based on the available scientific evidence and global experiences. Upon literature review there was no research done on the erudition and cognizance about the protocol during the COVID 19 pandemic among the dental students in Saudi Arabia, hence we choose this to study. Thus with this survey we can evaluate the dental students with their knowledge about COVID-19 and dentistry [9].

\section{AIM \& OBJECTIVES}

The main aim of this study is to assess the erudition and cognizance about the protocol during the 
COVID 19 pandemic among the dental students in Saudi Arabia. This can be attained by:

- Carrying out a survey to evaluate the knowledge of the dental students studying in Saudi Arabia about COVID-19 protocol.

- To determine the attitude of the dental students regarding the working guidelines and protocol to be followed while working in the dental clinic.

- Identifying the relation between the age of the dental doctor and their erudition about the $\mathrm{MOH}$ protocol for dental care.

- Identifying the relationship between the Genders of the dental doctor aand cognizance about COVID-19.

- Determining the awareness among the dental students and estimating their level of knowledge based on Saudi or non-Saudi national.

\section{METHODOLOGY \\ Research instrument}

A pre-designed questionnaire was circulated online using Google form to record the results of the survey of the erudition and cognizance about the protocol during the COVID 19 pandemic among the dental students in Saudi Arabia. This study was conducted in the year 2020. The questionnaire was originally designed in English language and later translated into Arabic language. The questionnaire included the questions related to the demographic data of the dental students followed by questions related to knowledge about COVID-19 and knowledge about relationship between COVID-19 and dentistry.
A total of about 195 dental students answered the questionnaire and their results were reported. The inclusion factor for this study was dental students residing in Saudi Arabia and above 18 years of age and the exclusion factor was dental practitioners, dental assistants, dental specialists or dental technicians; dental students residing outside Saudi Arabia and dental students below 18 years of age.

\section{STATISTICAL METHODS}

The results of the questionnaire survey of the erudition and cognizance about the protocol during the COVID 19 pandemic among the dental students in Saudi Arabia were recorded. The result of the survey was analysed using the SPSS software. The frequencies and percentage of the results of the erudition and cognizance about the protocol during the COVID 19 pandemic among the dental students in Saudi Arabia was done using the $\mathrm{P}$ value less than or equal to 0.05 .

\section{RESULTS}

The erudition and cognizance about the protocol during the COVID 19 pandemic among the dental students in Saudi Arabia can be evaluated using a questionnaire containing the socio-demographic characters and the knowledge based questions. The socio-demographic characters include age, gender, education and nationality.

\section{Demographic Data}

About 118 (59.9\%) of the dental students are in the age group $21-25$ years, while $41(21.5 \%)$ are in age group 26-30 years, $21(11.3 \%)$ are in age group 1920 years and $15(7.7 \%)$ are above 30 years. Majority $106(54.6 \%)$ of the dental students that participated in this study are males and $88(45.4 \%)$ of participants were females.

\begin{tabular}{|l|l|l|}
\hline DEMOGRAPHIC CHARACTERS & FREQUENCY & PERCENTAGE \\
\hline Age & & \\
$19-20$ years & 21 & 11.3 \\
21 - 25 years & 118 & 59.9 \\
26 - 30 years & 41 & 21.5 \\
$>30$ years & 15 & 7.7 \\
\hline Gender & & \\
Female & 88 & 45.4 \\
Male & 106 & 54.6 \\
\hline Education & & \\
I year & 4 & 2 \\
II year & 14 & 7.2 \\
III year & 24 & 12.4 \\
IV year & 9 & 4.6 \\
V year & 51 & 26.1 \\
Other & 93 & 47.7 \\
\hline Nationality & & \\
Saudi & 166 & 85.1 \\
Non-Saudi & 29 & 14.9 \\
\hline
\end{tabular}


About $93(47.7 \%)$ of the participants choose other, while $51(26.1 \%)$ are in V year, $24(12.4 \%)$ are in III year, $14(7.2 \%)$ are in II year $9(4.6 \%)$ are in IV year and $4(2 \%)$ are in I year of education. Around 166 $(85.1 \%)$ of the participants of this survey are Saudi national while $29(14.9 \%)$ of the dental students were Non-Saudi nationals.

\section{Knowledge about COVID-19}

$98.9 \%$ of the dental students know about the novel coronavirus (COVID-19), $94.8 \%$ of the participants know about the signs and symptoms of COVID-19, while $99 \%$ know about the severity of COVID-19, 99\% know about the mode of transmission of COVID-19, whereas $93.7 \%$ of the students know about the people who are at more risk to COVID-19.

\begin{tabular}{|l|l|l|}
\hline KNOWLEDGE ABOUT COVID 19 & YES \% & NO \% \\
\hline Do you know about novel coronavirus (COVID 19)? & 98.9 & 1.1 \\
\hline Do you know about the signs and symptoms of COVID 19? & 94.8 & 5.2 \\
\hline Do you know about the severity of COVID 19? & 99 & 1 \\
\hline Do you know the mode of transmission of COVID 19? & 99 & 1 \\
\hline Do you know the people who are at more risk to COVID 19? & 93.7 & 6.3 \\
\hline
\end{tabular}

\section{Attitude and knowledge about COVID-19 and Dentistry}

In order to determine about the attitude and knowledge about Covid 19 and its care in the dental department was surveyed using the following questionnaire. The results of which were like; $95.8 \%$ thinks that during the dental procedures the dentist, staff and patients are at high risk of transmitting covid 19, while $4.2 \%$ think it wont. $91.6 \%$ know that according to the ministry of health, dental services are limited to emergency or urgent care, while $8.4 \%$ have no idea about it. $75 \%$ knows that the guidelines during Covid19 pandemic are for the dentists, hygienists, dental assistants and dental technicians working in the dental department while $25 \%$ don't know about it. $80.2 \%$ know that the $\mathrm{MOH}$ guides dentist with this protocol to encourage a consistent approach in the management of emergency/urgent dental conditions whereas $19.8 \%$ don't know about this. $83.9 \%$ know that this protocol helps to identify the challenges that the COVID-19 epidemic presents for the provision of dental care while $16.1 \%$ have no idea about it. $87.5 \%$ of the dental students know that this protocol helps to provide and implement Infection Prevention and Control guidance during the management of dental emergency cases during COVID 19 outbreak. 86.9\% know that this guideline helps to deliver a quality control/audit tool for dental emergency care during the period of the COVID19 outbreak. $78.5 \%$ of the participants know that the emergency dental care includes includes uncontrolled bleeding, significant infection, facial swelling and oral facial trauma potentially compromising the patient's airway whereas $21.5 \%$ don't know about it. $80.9 \%$ know that mild and moderate symptoms can be treated by advising analgesics and antimicrobial. $89 \%$ know that $\mathrm{MOH}$ guidelines restrict the presence of unnecessary individuals in the dental clinic. 90.1\% know the dental protocol of COVID 19 suggests that Dentists should follow a strict infection control protocol guide with all emergency dental patients, while 9.9 dental students had no idea about it.

\begin{tabular}{|c|c|c|}
\hline KNOWLEDGE ABOUT COVID 19 AND DENTISTRY & $\begin{array}{l}\text { YES } \\
\%\end{array}$ & $\begin{array}{l}\text { NO } \\
\%\end{array}$ \\
\hline $\begin{array}{l}\text { Do you think that during the dental procedures, the dentist, staff and patients are at high risk of transmitting } \\
\text { Covid } 19 \text { ? }\end{array}$ & 95.8 & 4.2 \\
\hline Do you know that according to the ministry of Health, dental services are limited to emergency or urgent care? & 91.6 & 8.4 \\
\hline $\begin{array}{l}\text { Do you know that the guidelines during Covid } 19 \text { pandemic are for dentists, hygienists, dental assistants, and } \\
\text { dental technicians working in the dental department? }\end{array}$ & 75 & 25 \\
\hline $\begin{array}{l}\text { Do you know that the } \mathrm{MOH} \text { guides dentist with this protocol to encourage a consistent approach in the } \\
\text { management of emergency/urgent dental conditions? }\end{array}$ & 80.2 & 19.8 \\
\hline $\begin{array}{l}\text { Do you know that this protocol helps to identify the challenges that the COVID-19 epidemic presents for the } \\
\text { provision of dental care }\end{array}$ & 83.9 & 16.1 \\
\hline $\begin{array}{l}\text { Do you know that this protocol helps to provide and implement Infection Prevention and Control guidance } \\
\text { during the management of dental emergency cases during COVID } 19 \text { outbreak }\end{array}$ & 87.5 & 12.5 \\
\hline $\begin{array}{l}\text { Do you know that this guidelines helps to deliver a quality control/audit tool for dental emergency care during } \\
\text { the period of the COVID-19 outbreak? }\end{array}$ & 86.9 & 13.1 \\
\hline $\begin{array}{l}\text { Do you know that the emergency dental care includes includes uncontrolled bleeding, significant infection, } \\
\text { facial swelling and oral facial trauma potentially compromising the patient's airway? }\end{array}$ & 78.5 & 21.5 \\
\hline Do you know that mild and moderate symptoms can be treated by advising analgesics and antimicrobial? & 80.9 & 10.1 \\
\hline Do you know that MOH guidelines restrict the presence of unnecessary individuals in the dental clinic? & 89 & 11 \\
\hline $\begin{array}{l}\text { Do you know the dental protocol of COVID } 19 \text { suggests that Dentists should follow a strict infection control } \\
\text { protocol guide with all emergency dental patients }\end{array}$ & 90.1 & 9.9 \\
\hline
\end{tabular}


A small step was taken too aware the students about COVID-19 in the dental services by drafting a check-box to tick the things that they were aware off. The survey of the awareness questionnaire includes the results for the following questions. More than $90 \%$ of the dental students that participated in this survey knew about following hand hygiene, avoiding contact with eyes, mouth and nose to keep in mind while evaluating the patient. The participants were aware of using the protective measure to use by the dental professionals like surgical face masks $(91.7 \%)$, protective eye wear $(88.5 \%)$, gloves $(94.8 \%)$, head covers $(80.2 \%)$, eye protection (87.5), N-95 (83.9\%). The dental students were aware of dental radio-graphs to be used like $87.1 \%$ of panoramic radio-graphs, $44.6 \%$ of CBCT, $45.7 \%$ of occlusal radio-graphs.

\begin{tabular}{|l|l|l|}
\hline AWARENESS ABOUT COVID 19 IN DENTAL SERVICES & FREQUENCY & PERCENTAGE \\
\hline Things to keep in mind while evaluating the patient & & \\
Follow hand hygiene & 187 & 97.9 \\
avoid contact with eyes & 175 & 91.6 \\
avoid contact with mouth & 172 & 90.1 \\
avoid contact with nose & 176 & 92.1 \\
\hline Protective measures to be used for dental professionals & & \\
surgical face masks & 176 & 91.7 \\
protective eye wear & 170 & 88.5 \\
Gloves & 182 & 94.8 \\
Head covers & 154 & 80.2 \\
(N95-or higher respirator 95 & 161 & 83.9 \\
\hline Dental radio-graphs to be used & & \\
panoramic radio-graph & 162 & 87.1 \\
CBCT & 83 & 44.6 \\
Occlusal radio-graphs & 82 & 45.7 \\
\hline
\end{tabular}

\section{DISCUSSION}

In December 2019, a public health emergency intimidated the entire world and was referred to as a pandemic by the World Health Organization (WHO) [1]. This was initiated in the city of Wuhan, in China. The abstruse virus belonged to the family of coronaviridae, and its viral genome is a part of Betacoronavirus $[10,11]$. This virus was named COVID-19 and it is spherical in shape, with spikes of glycoproteins on its surface that appears like a crown and hence the name corona [12-14]. As per the report of WHO on $18^{\text {th }}$
July, there are a total of 13,876,441 and 593,087 confirmed deaths due to covid-19. About 216 countries or areas are affected with Covid-19 disease [1]. The statistics on $4^{\text {th }}$ August showed a total of 281,000 confirmed covid-19 cases in Saudi Arabia, with 244,000 people recovered from the disease and 2984 deaths in total and remaining under treatment. The highest number of cases were reported in Makkah province $(74,259)$ followed by Eastern province $(73,014)$, Riyadh province $(63,822)$, Aseer province $(19,985)$, Al Madinah province $(19,479)$.

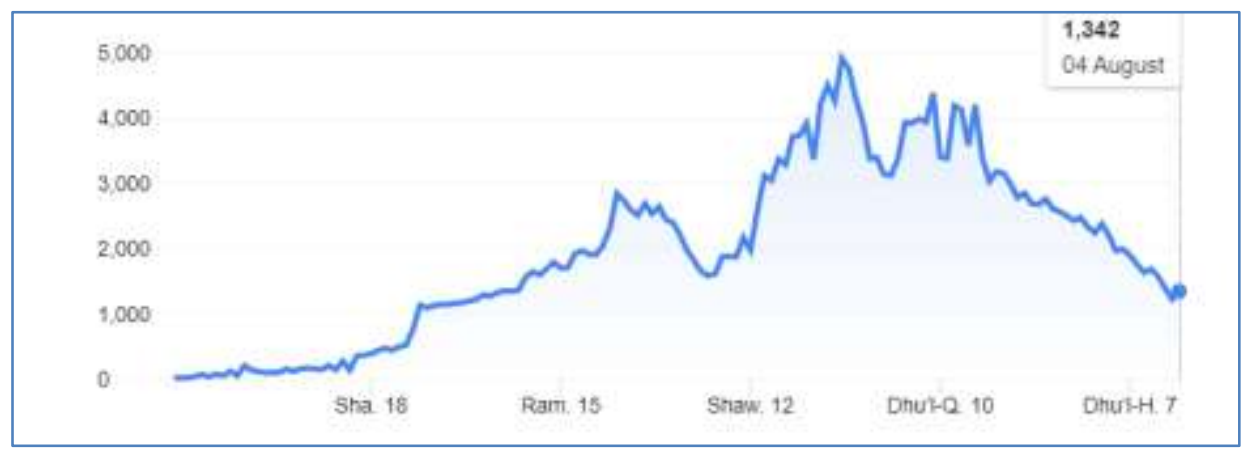

Graphical representation of COVID 19 cases in Saudi Arabia.

The basic aim and objective of this study is to provided details about the new coronavirus, its etiology, its incubation in humans, its symptoms, and the its mode of transmission. This information was given inorder to minimize the nosocomial spread in the dental department of hospitals and dental clinics. The knowledge of the protocol given by the Ministry of Health for dental health care is to formulate a contingency plan to follow the guideline before the patient's visit and after the treatment [9].

The virus is a zoonotic virus with human to human transmission and it basically uses the angiotensin converting enzyme-2 (ACE-2) that is present in lower respiratory tract as entry receptor [3]. A detailed knowledge about the COVID-19 virus is 
essential to avoid the transmission of virus in the dental clinic. The first point of contact between the dentist and the patient should be a telephonic conversation to promote teleconsulting [4]. A detailed history of the patient need to be taken about the signs and symptoms of COVID-19 like fever, cough, shortness of breath, runny nose, sore throat, lethargy, loss of smell and taste, diarhhea, vomiting, discolouration of fingers and toes [5]. If the patient confirms any of these symptoms then the appointment with the patient need to be cancelled until 3 weeks and only emergency cases need to be considered. If required, the patient should be instructed to take analgesics and topical agents through a teleconsultation [9].

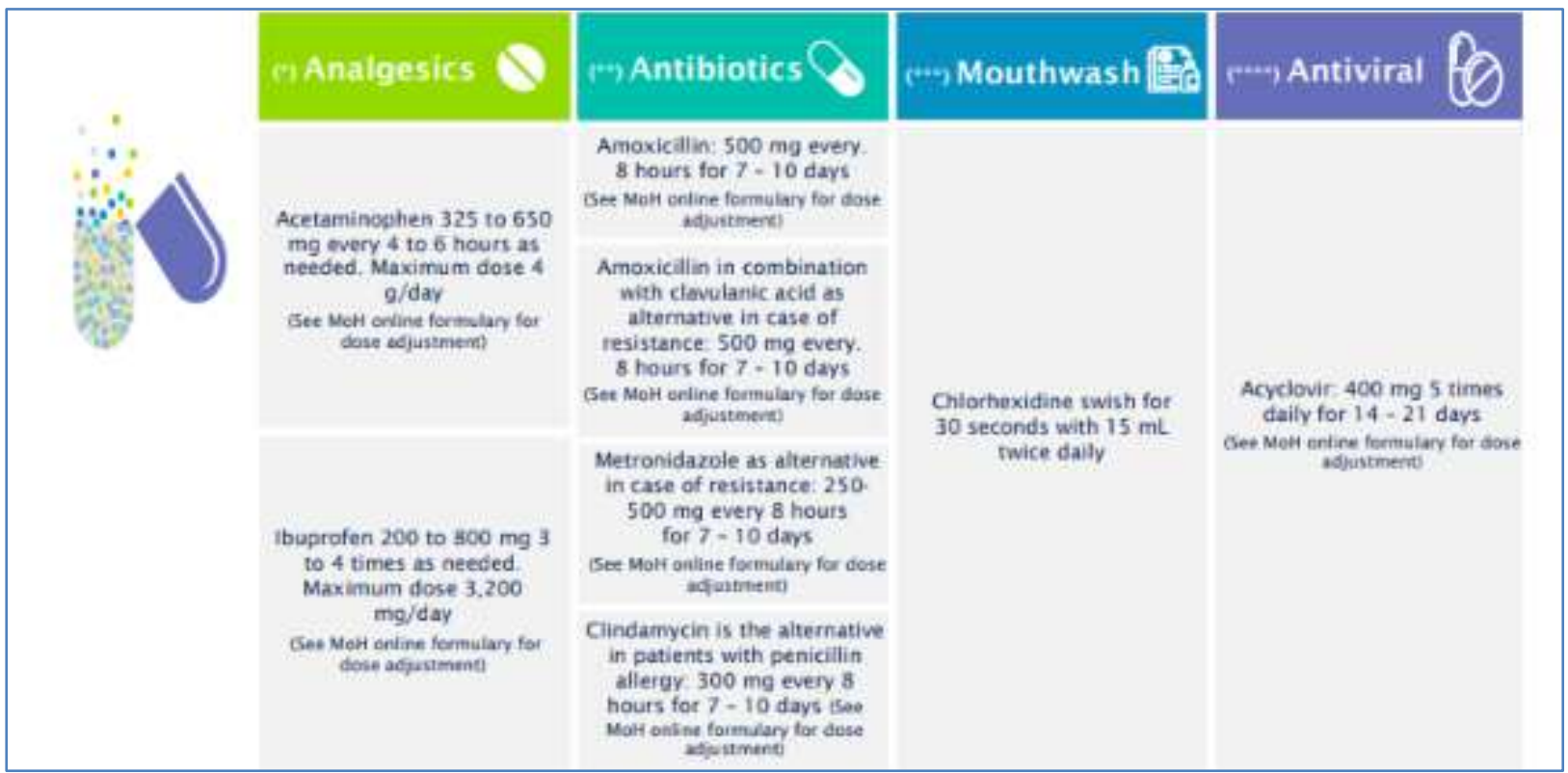

Emergency medicines to be prescribed to the patients

All the unnecessary items like the brochures, magazines should be removed and the chairs need to be placed at a distance of 6 feet. The dentist need to change their clothing once they enter the dental clinic and proper cleaning and sanitization need to be done of all the areas in the dental clinic [9]. The hand sanitizers and face masks and gloves to be provided to the patients and attendants. A isolation room should be present at the clinic for any possible infected patients with COVID-19 in-order to avoid contact with the clinic staff and other patients. The air purifiers and the air filters need to be provided for the filtration of air inside the clinic. Proper care need to be taken for the disposal of the infected waste material [9].

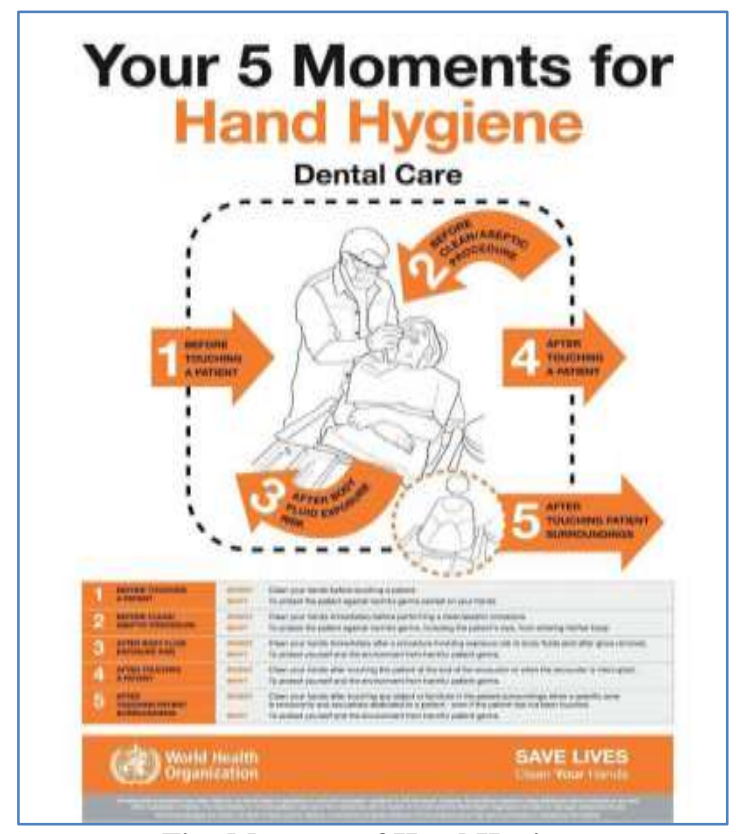

Five Moments of Hand Hygiene 


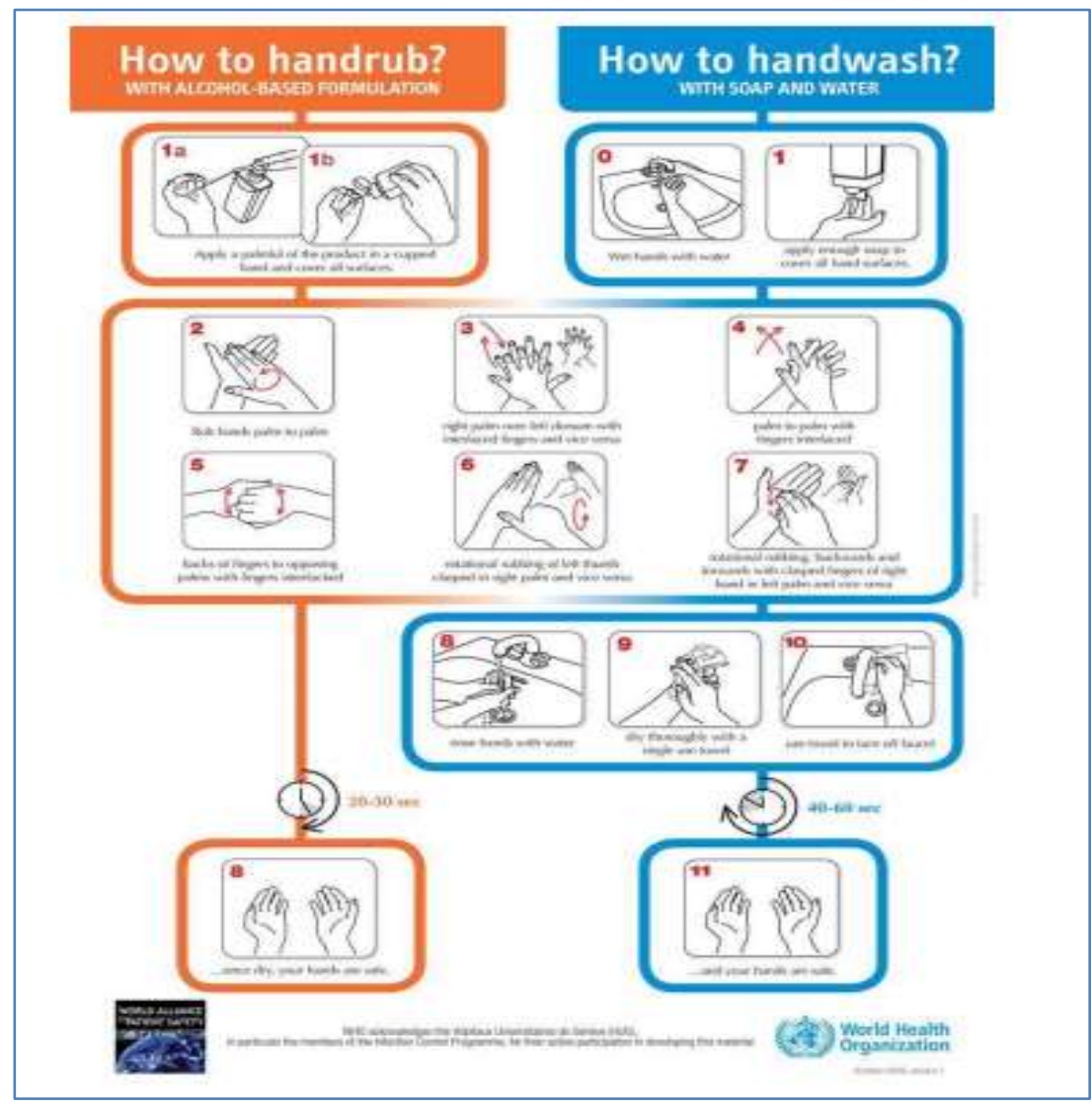

Combined Hand Hygiene Technique

The survey of this study showed results that more than $90 \%$ of the dental students have good knowledge about COVID-19 pandemic and dentistry. The dental students are well aware of the protocol to be followed during the dental practices. Very few surveys are done all across the world on the present topic as this is only half a year since emergence of the COVID-19 virus. The dental students have good erudition and cognizance about the protocol to be followed like following hand hygiene, avoiding contact with eyes, mouth and nose; using the protective measures like wearing surgical face masks, protective eye wear, gloves, head covers, eye protection and N95. They also have information about the diagnostic dental radiographs (panoramic, CBCT, occlusal) to be used during the procedure.

\section{CONCLUSION}

The COVID-19 virus is now a high-risk to the global population and health-care workers. In-order to control and develop a vaccine and treatment of this deadly virus, scientific research is going on throughout the world. The control the spread of this COVID-19 infection is significant and hence to attain this thorough knowledge and awareness about COVID-19 virus is important. Further study of the COVID-19 virus is to be carried out to analyse replication, transmission and pathogenesis of virus in the human beings.

\section{LIMITATIONS}

We cannot generalize our survey to the population of Saudi Arabia as it was conducted only in case of the dental students

\section{ACKNOWLEDGEMENT}

We would like to thank all the participants of Saudi Arabia to be a part of this survey and for their time and co-operation.

\section{ETHICAL CONSIDERATIONS Compliance with ethical standards}

Ethical approval: This article contains survey with human participants performed by all the participants of this research.

Conflict of interest: The authors do not have any commercial associations that might pose or create a conflict of interest with information presented in this communication. No intramural or extramural funding supported any aspect of this work.

\section{REFERENCES}

1. Coronavirus disease (COVID-19) outbreak situation: WHO. (2020)." 2020, https://www.who.int/emergencies/diseases/n ovel-coronavirus-2019. 
2. Baghizadeh, F. (2020). "What dentists need to know about COVID-19," Oral Oncology, vol. 105, Article ID 104741.

3. Riou, J., \& Althaus, C. L. (2020). Pattern of early human-to-human transmission of Wuhan 2019 novel coronavirus (2019-nCoV), December 2019 to January 2020. Eurosurveillance, 25(4), 2000058.

4. Kam, K. Q., Yung, C. F., \& Cui, L. A well infant with coronavirus Disease 2019 (COVID-19) with high viral load.[e-pub ahead of print]. Clin Infect Dis. doi, 10.

5. Chan, J. F. W., Yuan, S., Kok, K. H., To, K. K. W., Chu, H., Yang, J., ... \& Tsoi, H. W. (2020). A familial cluster of pneumonia associated with the 2019 novel coronavirus indicating person-toperson transmission: a study of a family cluster. The Lancet, 395(10223), 514-523.

6. Yang, J., Zheng, Y., Gou, X., Pu, K., Chen, Z., Guo, Q., \& Zhou, Y. (2020). Prevalence of comorbidities in the novel Wuhan coronavirus (COVID-19) infection: a systematic review and meta-analysis. International journal of infectious diseases.

7. “"Coronavirus disease (2019). (COVID-19): protecting hospitals from the invisible," 2020, https://annals.org/aim/fullarticle/2763036/co ronavirus-disease-2019-covid-19-protecting-

hospitals-from-invisible.

8. Centers for Disease Control and Prevention, Coronavirus Disease. (2019). (COVID-19), Centers for Disease Control and
Prevention, U.S. Department of Health \& Human Services, Atlanta, GA, USA, 2020, https://www.cdc.gov/coronavirus/2019ncov/infection-control/hcp-hand-hygiene-faq.html.

9. $\mathrm{MOH}$ guideline for dental care. (2020). https://www.moh.gov.sa/Ministry/MediaCenter/Pu blications/Documents/MOH-Guidelines-for-reopening-June-.pdf

10. Carrouel, F., Conte, M. P., Fisher, J., Gonçalves, L. S., Dussart, C., Llodra, J. C., \& Bourgeois, D. (2020). COVID-19: A recommendation to examine the effect of mouthrinses with $\beta$ cyclodextrin combined with citrox in preventing infection and progression.

11. Meng, L., Hua, F., \& Bian, Z. (2020). Coronavirus disease 2019 (COVID-19): emerging and future challenges for dental and oral medicine. Journal of Dental Research, 99(5), 481-487.

12. Center for Disease Control and Prevention, "Dental settings. (2020)." 2020, https://www.cdc.gov/coronavirus/2019ncov/hcp/dental-settings.html.

13. Ather, A., Patel, B., Ruparel, N. B., Diogenes, A., \& Hargreaves, K. M. (2020). Coronavirus disease 19 (COVID-19): implications for clinical dental care. Journal of endodontics.

14. Wang, P., Anderson, N., Pan, Y., Poon, L., Charlton, C., Zelyas, N., \& Babcock, H. (2020). The SARS-CoV-2 outbreak: diagnosis, infection prevention, and public perception. Clinical Chemistry, 66(5), 644-651. 